\title{
Pre-Weaning Morbidity and Mortality of Crossbred Calves in Bahir Dar Zuria and Gozamen Districts of Amhara Region, Northwest Ethiopia
}

\author{
Yeshwas Ferede ${ }^{1}$, Hailu Mazengia ${ }^{2}$, Tewodros Bimrew ${ }^{1}$, Addisu Bitew ${ }^{1}$, \\ Mohammed Nega ${ }^{1}$, Adebabay Kebede ${ }^{1}$ \\ ${ }^{1}$ Andassa Livestock Research Center, Bahir Dar, Ethiopia \\ ${ }^{2}$ Faculty of Agriculture and Environmental Science, Bahir Dar University, Bahir Dar, Ethiopia \\ Email: yeshwasferede@yahoo.com
}

Received 6 April 2014; revised 16 May 2014; accepted 22 June 2014

Copyright (C) 2014 by authors and OALib.

This work is licensed under the Creative Commons Attribution International License (CC BY).

http://creativecommons.org/licenses/by/4.0/

(c) (i) Open Access

\section{Abstract}

A cross-sectional study was conducted from September 2009 to August 2010 with the objective of determining calf morbidity and mortality rates, to investigate the potential risk factors for mortality and morbidity and to determine the type and prevalence of major diseases of crossbred calves in Bahir Dar Zuria and Gozamen districts of Amhara Region. A total of 148 respondents engaged in small holder crossbred dairying were interviewed using a structured questionnaire survey about their calf management practices and major calf health problems encountered. About 396 crossbred calves were considered for this study. The overall magnitude of morbidity and mortality rates of crossbred calves were $58.4 \%$ and $30.7 \%$, respectively. Higher mortality of crossbred calves was found in Gozamen district (39.6 \%) than in Bahir Dar Zuria district (29.9 \%). The major calf diseases found were diarrhea $(21.4 \%)$, pneumonia $(18.6 \%)$, septicemic conditions $(12.4 \%)$ and navel ill (8.1\%) and miscellaneous cases (39.5\%). Risk factors such as study location, blood level, age, colostrum feeding and time of colostrum feeding were found to have statistically significant $(p<0.05)$ effects on crossbred calf mortality rate in both districts. Exotic genetic influence, age, colostrum feeding and time of colostrum feeding were also the major risk factors found statistically significant $(p<0.05)$ to affect calf morbidity. In conclusion, the magnitude of calf morbidity and mortality rates found in this study were much higher than economically tolerable level and could affect the productivity of the dairy farms through mainly decreasing the availability of replacement stock. It is therefore, suggested that implementation of improved calf management practices and optimization of more adaptable blood level of crossbred cattle in the study areas would significantly reduce calf mortality and morbidity.

${ }^{*}$ Corresponding author.

How to cite this paper: Ferede, Y., Mazengia, H., Bimrew, T., Bitew, A., Nega, M. and Kebede, A. (2014) Pre-Weaning Morbidity and Mortality of Crossbred Calves in Bahir Dar Zuria and Gozamen Districts of Amhara Region, Northwest Ethiopia. Open Access Library Journal, 1: e600. http://dx.doi.org/10.4236/oalib.1100600 


\title{
Keywords
}

\section{Bahir Dar Zuria, Crossbred Calves, Gozamen, Morbidity Rate, Mortality Rate, Pre-Weaning}

\author{
Subject Areas: Veterinary Medicine, Zoology
}

\section{Introduction}

The productivity of cattle depends largely on their reproductive performance and the survival of calves [1] [2]. Calf morbidity and mortality are problems of major concern in all countries where cattle are raised under extensive husbandry practices [3], and the problem is more acute in developing countries due to bad calf management practices [4]. Calf mortality rates up to one year of age can go as high as $50 \%$ in the tropics due to bad management, poor adaptation of exotic breeds to the prevailing tropical environment and endemic diseases [5]. Calf replacement should be given appropriate attention since the availability of replacements heifers for a dairy herd markedly influences the ability of a dairy man to increase milk production by allowing him to practice elective culling of low producing cows [6]. Among other factors, calf diseases causing morbidity, mortality and fertility problems are among some of constraints faced in raising replacement stock. High incidence of calf morbidity and mortality incurs great economic loss to dairy producers. This arises from death loss, treatment cost, decreased life time productivity and survivorship [7]. It also causes the loss of genetic material for herd improvement and decreases the number of dairy heifers available for herd replacement and expansion.

Calf morbidity and mortality are perennial problems for dairy producers worldwide. A few studies conducted on calf mortality between 0 - 1 year in Ethiopia reported an overall mortality rates ranging from $10 \%$ to $33 \%$ [4] [8]-[10]. Previous estimates [5] indicated that a calf mortality rate of $20 \%$ can reduce net profit by $38 \%$ and therefore in a profitable dairy farm, calf mortality rate should be kept below 5\% [8] [11]. According to ILCA [12]) calf morbidity and mortality were ranked next to mastitis as the second biggest problem for dairy production in Ethiopia. Scours in neonatal period and Pneumonia in older calves are known to be responsible for most of calf hood morbidity and mortality [13]-[15]. Similar findings were reported from Ethiopia [16]-[19]. Several environmental and managerial factors act as risk factors for the occurrence of calf morbidity and mortality [7] [20] [21]. In a study that included stillbirth and abortion, mortality rate was reported as high as 67\% [22].

Calf diseases that cause morbidity and mortality are the results of complex interaction of the management practices, environment, infectious agents and the calf itself. Therefore, this study was mostly done on smallholder dairy farmers in two districts of Amhara Regional State, Northwest Ethiopia with the following major objectives:

- To determine the magnitude of pre-weaning crossbred calf morbidity and mortality rates.

- To determine the types and prevalence of major disease of pre-weaning calves.

- To assess associated risk factors for pre-weaning crossbred calf morbidity and mortality.

\section{Materials and Methods}

\subsection{Study Area Description}

This study was conducted in two model districts of Amhara region, Northwest Ethiopia. These districts were Bahir Dar and Gozamen which were selected purposively due to their geographic location representing mid and high altitude areas. In the study districts farmers were selected and included in small-holder dairy production packages launched and implemented by Regional government through distributing pregnant cross bred heifers to farmers. Bahir Dar zuria district is located, $565 \mathrm{~km}$ North West of the capital Addis Ababa. The mean altitude of the district is 1800 meter above sea level and the temperature of the district ranges from $10^{\circ} \mathrm{C}$ to $380^{\circ} \mathrm{C}$ along the year with annual rain fall of $800-1250 \mathrm{~mL}$. The livelihood of major section of the population in the area depends on crop-livestock mixed farming. The district comprises 121,528 Cattle, 2346 Shoats, 37,839 Equine and 62,012 Poultry (Bahir Dar zuria BoA report, 2002).

Gozamen District is also located in Northwest Ethiopia at altitude of the district is 2400 meter above sea level. The average temperature for the area is $8{ }^{\circ} \mathrm{C}$ to $21^{\circ} \mathrm{C}$ and the area receives with a minimum and maximum annual rain fall of 1448 to $1808 \mathrm{~mm}$ respectively [23]. The livelihood of the major section of the population in the area 
depends on crop-livestock mixed farming. The district comprises 160,067 Cattle, 113,738 Shoats, 21,839 Equine, 46,368 Poultry (Gozamen woreda BoA report, 2002).

\subsection{Study Animals, Study Design and Sampling Technique}

Study animals were crossbred dairy calves (Local Zebu $\times$ Holstein-Friesian) of pre-weaning age in Bahir Dar, zuria and Gozamen districts. A cross-sectional study was carried out to determine the morbidity, mortality and major health problems of calves. Study sites and households were selected purposively based on the availability of cross breed animals and geographic locations. A total of 148 respondents who owned crossbred calves of preweaning age (below 15 months) were sampled and interviewed, and 396 cross bred calves (173 in Gozamen; 223 in Bahir Dar Zuria) were used for this study.

\subsection{Data Collection}

A structured questionnaire which has been composed of various questions focused on calf management and health concerns was administered to 148 households. Major risk factors including location, season of calf birth, condition of birth, sex, age, exotic genetic influence, colostrum feeding, time and method of colostrums feeding were the different variables covered during the interview. Data on history of calf deaths, history of illness, and quantity of milk feeding, feeding and type of feeds, watering and health care were also recorded. Major diseases syndromes of calves were recorded during the data collection process and were summarized and categorized in to four disease conditions/syndromes based on owners' traditional disease description knowledge with cross referenced to scientific disease interpretation. These were, Diarrhea, Pneumonia, Septicaemic condition and Navel ill (Omphalitis).

\subsection{Data Management and Analysis}

All data were first entered and managed using Microsoft Excel and analysis of data were made through Statistical Package for Social Sciences software version 16 (SPSS 16) [24]. To measure crude calf morbidity, mortality and disease conditions of calves, descriptive statistics was employed. While analysis of variance using GLM of SPSS was employed to measure the effect of risk factors (Milk shed location, \% of exotic blood, season of birth, age, colostrum feeding and age at which colostrums feeding on calf morbidity, mortality and disease conditions of calves. A significance level $(\mathrm{p}<0.05)$ and confidence level $(95 \%)$ was set to determine the presence or absence of statistically significant difference between the given parameters.

\section{Results}

\subsection{Description of Household and Livelihood Characteristics}

The majority of respondents were male (72.5\%) and the rest (27.5\%) were female. The average age of the respondents was 44.13 years with a minimum and maximum of 20 to 80 years respectively. As far as households literacy rate is concerned; it was composed of illiterate (50.0\%), read and write (23.6\%), primary (13.6\%) and secondary school completed (12.8\%). In the surveyed districts, average family size was 6.36 and ranging from 1 to 15 . An average land holding per household was 2.25 ha. About $91.1 \%$ of households' livelihood is entirely dependent on agriculture. Respondents who are engaged in other non-agricultural activities were; Merchant (2.7\%), Retired (2.7\%) and Government employed (2.5\%). The average number of local and crossbred calves per household was 1.54 and 1.51, respectively. While, the average number of local and cross bred cows per household was 2.02 and 1.53 TLU, respectively.

\subsection{Crossbred Calves Management Practices in the Study Areas}

The study indicated that only $39.2 \%$ of the respondents know the importance of colostrum feeding. Of those do have knowledge, only $10.1 \%$ feed colostrum to their calves immediately after birth within six hours. Method of milk feeding is suckling (75.0\%) and bucket feeding (25.0\%). In the surveyed districts, $48.0 \%$ of the respondents feed their calf only hay and straw, $31.1 \%$ improved forage with straw and hay, and $10.8 \%$ of respondents feed concentrate with hay and straw. Of the total respondents, $45.3 \%$ explained that frequent mortality was observed in male than female calves. On the other hand, $25.0 \%$ of the respondents explained frequent mortality 
was observed in females than males and the remaining $29.7 \%$ explained as both sexes were equally vulnerable to mortality. Thirty-six percent of the respondents explained that frequent mortality was observed in calves of below 3 months of age. On the other hand, 21.8\% respondents explained as mortality was frequent from 3 to 6 months of age.

\subsection{Crude Calf Morbidity, Mortality and Major Calf Diseases}

The results of this study revealed that crude morbidity and mortality of pre-weaning age were $58.4 \%$ and $30.7 \%$, respectively. The major calf diseases reported in this study were Omphalitis (8.1\%) septicemic conditions (12.4\%) pneumonia (18.6\%), diarrhea (21.4\%) and miscellaneous cases (39.5\%) (Table 1).

\subsection{Association of Potential Risk Variables with Morbidity and Mortality}

A total of seven different potential risk factors (study location, \% of exotic genetic influence, season, sex and age, colostrum feeding and time of colostrum feeding) were investigated for their association with the occurrence of morbidity, mortality and major disease conditions of calves. Five factors (study location, exotic genetic influence, age, colostrum feeding and time of colostrum feeding) were found significantly $(\mathrm{p}<0.05)$ associated with calf mortality (Table 2). The other four (4) risk factors (exotic genetic influence, age, colostrum feeding and age at which colostrum feeding) were also found statistically significant $(\mathrm{p}<0.05)$ with calf morbidity (Table 2).

\subsection{Major Disease Conditions of Calves and Associated Risk Factors}

The major calf diseases reported in this study were Diarrhea (21.4\%), Pneumonia (18.6\%), Septicaemic conditions (12.4\%) and Omphalitis (8.1\%). An association of putative risk factors with major diseases conditions of calves was tested (Table 3). Among analyzed risk factors, exotic blood influence, age, season, colostrum feeding and time of colostrum feeding were found statistically significant $(\mathrm{p}<0.05)$ with calf diarrhoea. Season and colostrum feeding were risk factors which were found to have statistically significant effects on $(p<0.05)$ with calf pneumonia (Table 3).

\section{Discussion}

The crude calf morbidity (58.4\%) and mortality rates (30.7\%) found in this study found were much higher than the 3 to $5 \%$ calf mortality that can be achieved through good calf management and above the economically tolerable level at least by the standard of the western production systems [25] and even much higher than the reports of calf mortality (7\% to $25 \%$ ) in developing countries under poor management and major disease problems [26] and $18.0 \%$ of calf mortality rate in dairy farms of Debre Zeit and its surroundings [6]. However, the current mortality rate is found relatively lower than the previous report [5], calf mortality rates up to one year of age can go as high as $50 \%$ in the tropics due to bad management, poor adaptation of exotic breeds to the prevailing tropical environment and endemic diseases. This discrepancy might be attributed to differences in calf management

\begin{tabular}{|c|c|}
\hline Crude morbidity and mortality & Percentage \\
\hline Morbidity & 58.4 \\
\hline Mortality & 30.7 \\
\hline Major calf diseases & Relative morbidity percentage \\
\hline Omphalitis (Naval ill) & 8.1 \\
\hline Septicemic condition & 12.4 \\
\hline Calf pneumonia & 18.6 \\
\hline Calf diarrhea & 21.4 \\
\hline Miscellaneous cases & 39.5 \\
\hline
\end{tabular}


Table 2. Association of potential risk variables with calf morbidity and mortality based on GLM, multivariate analysis.

\begin{tabular}{|c|c|c|c|}
\hline \multirow[t]{2}{*}{ Risk factors } & \multicolumn{3}{|c|}{ Mortality and morbidity } \\
\hline & $\mathrm{N}$ & Morbidity (\%) & Mortality (\%) \\
\hline Location & & NS & ${ }^{*}$ \\
\hline Bahir Dar zuria & 278 & 56.5 & 28.1 \\
\hline Gozamen & 119 & 65.0 & 37.0 \\
\hline Exotic blood level (\%) & & $*$ & $*$ \\
\hline Up to 25 & 85 & $47.1^{\mathrm{a}}$ & $18.8^{\mathrm{a}}$ \\
\hline$>25-50$ & 103 & $55.3^{\mathrm{a}}$ & $25.2^{\mathrm{b}}$ \\
\hline$>50-75$ & 167 & $61.1^{\mathrm{b}}$ & $34.7^{\mathrm{c}}$ \\
\hline$>75$ & 42 & $78.6^{c}$ & $52.3^{\mathrm{d}}$ \\
\hline Season & & Ns & NS \\
\hline Wet season & 121 & 65.3 & 28.1 \\
\hline Dry season & 88 & 55.7 & 33.0 \\
\hline Sex of calf & & Ns & NS \\
\hline Male & 230 & 68.2 & 38.1 \\
\hline Female & 166 & 42.5 & 26.3 \\
\hline Age of calf (in month) & & $*$ & $*$ \\
\hline Up to 3 & 75 & $64.3^{\mathrm{a}}$ & $39.3^{\mathrm{a}}$ \\
\hline$>3-6$ & 115 & $52.4^{\mathrm{b}}$ & $30.4^{\mathrm{b}}$ \\
\hline$>6-12$ & 158 & $39.1^{\mathrm{cb}}$ & $18.5^{\mathrm{c}}$ \\
\hline$>12$ & 48 & $21.5^{\mathrm{c}}$ & $14.5^{\mathrm{c}}$ \\
\hline Colostrum feeding & & $*$ & * \\
\hline Yes & 172 & 42.8 & 33.9 \\
\hline $\mathrm{No}^{* *}$ & 224 & 68.0 & 66.1 \\
\hline Time of colostrums feeding & & * & * \\
\hline$<6 \mathrm{hr}$ & 75 & 39.0 & 15.8 \\
\hline$>6 \mathrm{hr}$ & 97 & 60.5 & 32.0 \\
\hline
\end{tabular}

$\mathrm{N}=$ number of observations; ${ }^{*}=$ Significant $(\mathrm{p}<0.05) ;{ }^{\mathrm{NS}}=$ not significant $(\mathrm{p}>0.05) ;{ }^{* *}=$ Calves totally inhibited from colostrum; Percentage with different superscripts letters (a, b, c, d) within the same column and class are statistically different.

practices across the study location, and agro-ecological variation. The present finding agrees with other studies conducted on calf mortality between 0 - 1 year in Ethiopia, reported an overall mortality rates ranging from 10\% to 33\% [4] [8]-[10] The magnitude of crude morbidity reported in this study slightly agrees with the finding of Wudu et al. [6], who reported 61.5\% of crude morbidity rate and Virtala et al. [27] and Debnath et al. [9] reported $52 \%$ rate of crude morbidity in crossbred calves.

The major surveyed calf diseases were diarrhea (21.4\%), septicaemic conditions (12.4\%), pneumonia (18.6\%), naval ill (8.1\%) and miscellaneous cases (39.5\%). Except calf diarrhea, the current prevalence of surveyed calf diseases are higher than the results reported by Wudu et al. [6] in dairy farms in Debre Zeit and its surroundings, in which calf diarrhea, pneumonia, septicaemic condition and naval ill were $42.9 \%, 4.9 \%$, 3.9\% and 3.7\% respectively. The discrepancy might be attributed to differences in knowledge of calf management practices, agroecology and study design employed (the previous study used longitudinal study design to determine the incidence rate of these diseases, where as this study used cross-sectional study design by using questionnaire to determine the prevalence of these diseases). The predominance of calf diarrhea followed by pneumonia as a major calf health threat reported in this study is consistent with various reports in Ethiopia and many other studies elsewhere, which reported diarrhea and pneumonia as the first and second important disease complexes that affect calf health [9] [14] [15] [17] [20].

Risk factors statistically associated with calf mortality were study location, exotic genetic influence, age, co- 
Table 3. Association of potential risk variables with major disease conditions of calves based on GLM, multivariate analysis.

\begin{tabular}{|c|c|c|c|c|}
\hline \multirow[b]{2}{*}{ Risk factors } & \multicolumn{4}{|c|}{ Major diseases of calves (\%) } \\
\hline & Pneumonia & Diarrhea & Omphalitis & Septicemic condition \\
\hline Location & Ns & ${ }^{*}$ & Ns & Ns \\
\hline B/Dar zuria & 17.4 & 19.6 & 8.6 & 14.6 \\
\hline Gozamen & 25.3 & 30.3 & 6.7 & 22.3 \\
\hline Exotic blood level (\%) & Ns & * & Ns & Ns \\
\hline Up to 25 & 7.5 & $14.2^{\mathrm{a}}$ & 4.7 & 7.6 \\
\hline$>25-50$ & 23.1 & $18.9^{\mathrm{ab}}$ & 12.6 & 19.3 \\
\hline$>50-75$ & 20.9 & $26.1^{\mathrm{b}}$ & 7.2 & 22.2 \\
\hline$>75$ & 19 & $30.0^{\mathrm{c}}$ & 7.0 & 25.0 \\
\hline Season & Ns & ${ }^{*}$ & Ns & Ns \\
\hline Wet season & 16.2 & 26.1 & 7.8 & 18.8 \\
\hline Dry season & 29.2 & 15.6 & 8.4 & 18.2 \\
\hline Sex of calf & Ns & Ns & Ns & Ns \\
\hline Male & 14.0 & 28.3 & 6.8 & 22.0 \\
\hline Female & 13.7 & 27.4 & 10.6 & 15.6 \\
\hline Age of calf (in month) & ${ }^{*}$ & $*$ & Ns & Ns \\
\hline Up to 3 & $22.6^{\mathrm{a}}$ & $28.1^{\mathrm{a}}$ & 11.2 & 15.9 \\
\hline$>3-6$ & $16.9^{\mathrm{b}}$ & $18.6^{\mathrm{b}}$ & 11 & 14.8 \\
\hline$>6-12$ & $11.9^{\mathrm{c}}$ & $12.2^{\mathrm{b}}$ & 3.4 & 20.5 \\
\hline$>12$ & $8.2^{\mathrm{cb}}$ & $7.5^{\mathrm{c}}$ & 4.8 & 26.4 \\
\hline Colostrum feeding & $*$ & * & Ns & Ns \\
\hline Yes & 10.0 & 9.0 & 12.8 & 21.9 \\
\hline No ${ }^{* *}$ & 21.3 & 29.6 & 5.0 & 13.7 \\
\hline Time of colostrums feeding & Ns & * & Ns & Ns \\
\hline$<6 \mathrm{hr}$ & 16.0 & 13.4 & 10.8 & 12.8 \\
\hline$>6 \mathrm{hr}$ & 23.8 & 24.2 & 9 & 19.5 \\
\hline
\end{tabular}

$\mathrm{N}=$ number of observations; ${ }^{*}=$ Significant $(\mathrm{p}<0.05)$; NS = not significant $(\mathrm{p}>0.05) ;{ }^{* *}=$ Calves totally inhibited from colostrums; Percentage with different superscripts letters (a, b, c) within the same column and class are statistically different.

lostrum feeding and time of colostrum feeding. Exotic genetic influence, calf age, colostrum feeding and duration of at which colostrum feeding were risk factors found statistically associated with calf morbidity. Mortality differences were found statistically significant between study districts. Higher mortality and morbidity was recorded from Gozamen district, despite its agro-climatic condition is seemingly favorable for cross bred calves due to lower daily temperature ranges than Bahir Dar district. The variation of mortality among study areas might be due to differences in calf management practices, number and exotic genetic influence of crossbred calves kept. The relatively poor over all calf management practices observed in Gozamen district may contribute for high mortality and morbidity rates observed in this study. On the other hand, the degree of mortality and morbidity rates were found with increment trends as blood level of cross bred calves increases and a declining trend as age increases. The higher magnitude of mortality and morbidity was recorded from calves of above $75 \%$ exotic genetic influence than other percentages of exotic blood level influence. This is due to the fact that, the tropical environment for which temperate and cross breeds are not well adapted might have been an additional stress to increase the risks of mortality and morbidity [6]. Similar reports emphasized that keeping crossbred dairy cows of the intermediate exotic blood (62.5\% - 75\%, Friesian inheritance) is suggested for better production [28]. The declining trend of mortality and morbidity as age increases found in this study is in line with the previous finding [7], $60 \%$ of all deaths occurred in the first months of life over a period of four months.

Colostrum as well as age at colostrum feeding was found statistically significant with calf morbidity and 
mortality, higher mortality and morbidity was recorded from calves inhibited from colostrum feeding. Several studies have reported the effect of delayed colostrum intake on calf health and survival [6] [14] [29]. Each hour of delay in colostrum ingestion in the first 12 hours of age increased the chance of a calf becoming ill by $10 \%$ [26]. Calves with inadequate colostral immunoglobulin concentration within 24 hours of birth were at greater risk of neonatal morbidity and mortality, pre-weaning morbidity and morbidity and respiratory morbidity [29]. Moreover, an association of calf mortality with delayed colostrum intake in weaned calves was also reported [6].

\section{Conclusion and Recommendation}

In conclusion, the degree of morbidity and mortality found in this study were much higher than the economically tolerable level. This is a great hindrance to improve dairy production and productivity throughout these study areas. It has also been found that factors such as exotic genetic influence, colostrum feeding, time of colostrums feeding and age of calf were the most important determinant factors of calf mortality, morbidity and disease conditions. Higher mortality and morbidity rates were recorded in calves having above $75 \%$ exotic genetic influence. Therefore, to reduce calf morbidity and mortality in the study areas, implementation of improved crossbred calf management practices such as allowing calves to take adequate colostrums within 24 hours of birth, improved health care, housing and feeding through sustainable training and optimization of appropriate crossbreeding should be warranted. As calf diarrhea and pneumonia were found to be the major diseases and of which are both etiologically complex diseases, a more comprehensive study is suggested to identify the major infection causing agents. Further comprehensive research on the role and association of different epidemiological factors such as calf (host factor), environmental and etiological factors that might influence calf morbidity and mortality is also recommended.

\section{Acknowledgements}

We would like to extend our thanks to Amhara Regional Agricultural Research Institute for funding of this study. We thank Mehari Ayalew, Eyaya Molla and Wondmagene Mengesha for their kind help during data collection and data entry.

\section{References}

[1] Arthur, G.H., Noakes, D.E. and Person, H. (1989) Veterinary Reproduction and Obstetrics. 6th Edition, Baillier Tindall, London, 344-442.

[2] Mukasa-Mugerwa, E. (1989) A Review of Reproductive Performance of Female Bos indicus (Zebu) Cattle. Monograph No. 6, ILCA, Addis Ababa, Ethiopia, 101-104.

[3] Radostits, O.M. (2001) Health and Production Management of Dairy Calves and Replacement Heifers. Herd Health, 3rd Edition, W.B. Saunders, Philadelphia, 255-365.

[4] AACM (Australian Agricultural Consulting and Management) (1985) Project Preparation Report: Dairy Rehabilitation and Development Project Annexes. Vol. 2, AACM Co. Ltd., Adelaide.

[5] Radostits, O.M., Leslie, K.E. and Fetrow, J. (1994) Health Management of Dairy Calves and Replacement Heifers. Herd Health, 2nd Edition, W.B. Saunders Company, Philadelphia, 183-214.

[6] Temesgen, W. (2004) Calf Morbidity and Mortality in Dairy Farms in Debre Zeit and Its Envirions. MSc Thesis, Faculty of Veterinary Medicine, Addis Ababa University, Addis Ababa, 1-47.

[7] Waltner-Toews, D., Martin, S. and Merk, A.H. (1986) Effect of Calf Hood Disease on Survivorship and Age at First Calving. Canadian Journal of Veterinary Research, 50, 314-317.

[8] Alemu, G.W. and Teshome, Y. (1987) Note on Calf Mortality Rate at Two IAR Livestock Stations, Holetta and Adamitulu. Proceedings of the 1st National Livestock Improvement Conference, IAR, Addis Ababa, 76-80.

[9] Fikadu, S. and Tefera, G.M. (1993) Causes of Calf Mortality in Adamitullu-Abernossa Cattle Ranch. Proceedings of the 7th Conference of Ethiopian Veterinary Association (EVA), Addis Ababa, 105-109.

[10] Mengesha, F. (1993) A Retrospective Study of Cattle Mortality at Holetta Research Center. Proceedings of the 7th Annual Conference of Ethiopian Veterinary Association (EVA), Addis Ababa, 101-104.

[11] Kifaro, G.C. and Temba, E.A. (1990) Calf Mortality and Culling Rates in Two Dairy Farms in Iringa Region, Tanzania. Proceedings of the Tanzanian Society of Animal Production (TSAP), Tanzania, 138-146.

[12] ILCA (International Livestock Center for Africa) (1994) ILCA Annual Program Report 1993/1994. Addis Ababa, 73-74. 
[13] Debnath, N.C., Sil, B.K., Seslim, S.A. Prodhan, M.A.M. and Howlader, M.M.R. (1990) A Retrospective Study of Calf Mortality and Morbidity on Smallholder Traditional Farms in Bangladesh. Preventive Veterinary Medicine, 9, 1-7. http://dx.doi.org/10.1016/0167-5877(90)90037-I

[14] Olsson, S.O., Viring, S., Emanuelsson, U. and Jacobsson, S.O. (1993) Calf Disease and Mortality in Swedish Dairy Herds. Acta Veterinaria Scandinavica, 34, 263-269.

[15] Sivula, N.J., Ames, T.R., Marsh, W.E. and Werdin, R.E. (1996) Descriptive Epidemiology of Morbidity and Mortality in Minnesota Dairy Heifers Calves. Preventive Veterinary Medicine, 27, 155-171. http://dx.doi.org/10.1016/0167-5877(95)01000-9

[16] Amoki, O.T. (2001) Management of Dairy Calves in Holleta Area, Central Highlands of Ethiopia. M.Sc. Thesis, Faculty of Veterinary Medicine, Addis Ababa University, Debre Zeit.

[17] Hussein, N. (1998) A Study on Calf Mortality at Adamitulu Livestock Research Center. Proceeding of 5th Conference of Ethiopian Society of Animal Science (ESAP), Addis Ababa, 15-17 May 1997, 157-162.

[18] Lemma, M., Kassa, T. and Tagagne, A. (2001) Clinically Manifested Major Health Problems of Crossbred Dairy Herds in Urban and Peri-Urban Production Systems in the Central High Land of Ethiopia. Tropical Animal Health and Production, 33, 85-93. http://dx.doi.org/10.1023/A:1005203628744

[19] Shiferaw, Y., Yohannes, A., Yilma, Y., Gebrewold, A. and Gojjam, Y. (2002) Dairy Husbandry and Health Management at Holleta. Proceeding of the 16th Conference of the Ethiopian Veterinary Association, Addis Ababa, 5-6 June 2002, 103-119.

[20] Lance, S.E., Miller, G.Y., Mncock, D.D., Bartlet, P.C. and Heider, L.E. (1992) Salmonella Infection in Neonatal Dairy Calves. Journal of the American Veterinary Medical Association, 201, 864-868.

[21] Bruning-Fann, C. and Kaneene, J.B. (1992) Environmental and Managemental Risk Factors Associated with Morbidity and Mortality in Perinatal and Preweaning Calves: A Review from an Epidemiological Perspective. Veterinary Bulletin, 62, 399-403.

[22] Gryeels, G. and de Boodet, K. (1986) Integration of Crossbred Cows (Boran and Freisian) on Smallholder Farms in Debre Zeit Area of the Ethiopian Highlands. ILCA Highland Program Report, ILCA, Addis Ababa.

[23] CSA (Central Statistical Agency) (2006) Report on Livestock Resources of Amhara Region. 23-112.

[24] Statistical Package for Social Sciences (SPSS) (2007) SPSS User’s Guide (SAS) Institute Inc.

[25] Heinrichs, A.J. and Radostits, O.M. (2001) Health and Production Management of Dairy Calves and Replacement Heifers. In: Radostits, O.M., Ed., Herd Health, Food Animal Production Medicine, W.B. Saunders Company, Philadelphia, 333-395.

[26] Otte, M.J. and Chilonda, P. (2002) Cattle and Small Ruminant Production System in Sub-Sharan Africa—A Systemic Review. FOA, Rome.

[27] Virtala, A.M., Mechor, G.D., Grohn, Y.Y and Erb, H.N. (1996) Morbidity from Non-Respiratory Diseases and Mortality in Dairy Heifers during the First Three Months of Life. American Journal of Veterinary Research, 208, $2043-2046$.

[28] Yahya, A.K.H., Tetraifl, M.E.L. and Siddig, F.S. (2011) Performance of Kenana X Friesian Cross-Bred Cattle in Central Sudan. Online Journal of Animal and Feed Research, 6, 274-279.

[29] Wittum, T.E. and Perino, L.J. (1995) Passive Immune Status at Postpartum Hour 24 and Long Term Health Performance or Calves. American Journal of Veterinary Research, 56, 1149-1154. 